\title{
RESENHA/REVISIÓN/REVIEW
}

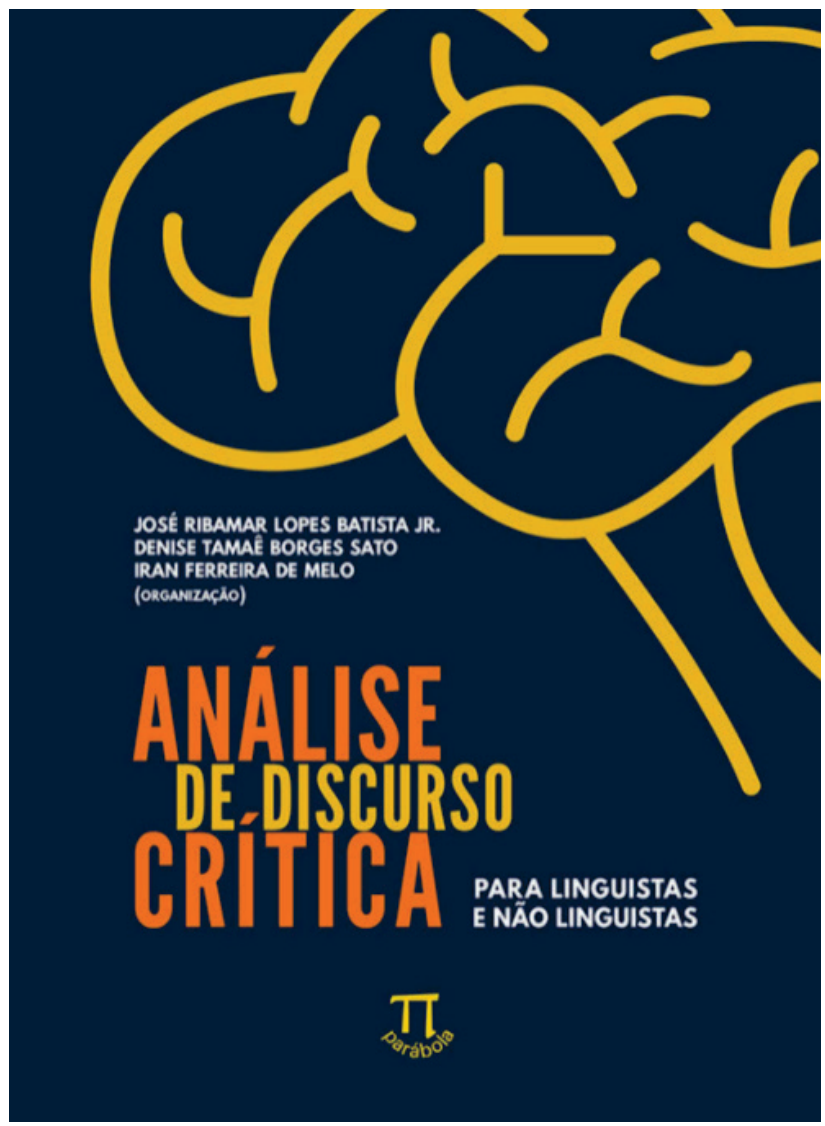

BATISTA JR, J. R. L.; SATO, D. T. B.; MELO, I. F. (org.). Análise de discurso crítica para linguistas e não linguistas. São Paulo: Parábola, 2018. 224p. ISBN 978-85-7934-147-2.

O livro que ora apresentamos, Análise de discurso crítica para linguistas e não linguistas, foi organizado pelos pesquisadores José Ribamar Lopes Batista Junior, Denise Tamaê Borges Sato e Iran Ferreira de Melo, e publicado em 2018 pela Parábola. De maneira clara e consistente, a obra contribui substancialmente para que os leitores das mais distintas áreas compreendam a análise de discurso crítica (ADC), cujo maior expoente é o britânico Norman Fairclough, como uma abordagem de caráter transdisciplinar e emancipatório que estuda a língua em uso, sendo esta permeada por relações de poder.

$\mathrm{Na}$ Introdução, os organizadores utilizam uma metáfora bastante oportuna para apresentar a análise de discurso (AD) aos linguistas e aos não linguistas: a $\mathrm{AD}$ como "um grande guarda-chuva" que acomoda distintas perspectivas, como a linguística sistêmicofuncional, a análise de discurso multimodal, a análise da narrativa, a análise de discurso mediada, a análise da conversação, a análise de corpus e a análise de discurso crítica. Embora a ADC possua diferentes vertentes - como a perspectiva histórica, de Wodak, a

\footnotetext{
* Doutoranda pelo Programa de Pós-Graduação em Linguística Aplicada da Universidade Estadual do Ceará (POSLA/UECE). Professora de Língua Portuguesa da Secretaria de Educação do Ceará (SEDUC/CE). E-mail: adrika.pereiral3@gmail.com.
} 
abordagem sociocognitiva, de van Dijk, a representação de atores sociais, de van Leeuwen, e a linguística de corpus, de Mautner -, os organizadores esclarecem que se convencionou chamar de ADC a proposta dialético-relacional, de Fairclough, a qual apresenta como precursora, no Brasil, a pesquisadora Izabel Magalhães, tradutora, inclusive, da densa obra faircloughiana Discourse and Social Change.

Batista Jr., Sato e Melo declaram que “[...] a ADC busca a explanação dos fenômenos sociais, desvelando o modo como o discurso, enquanto linguagem em uso, participa dessa construção, estabilizando distorções sociais” (p. 9). Lembram aqui os efeitos dos textos, sua capacidade de (re)construir novas articulações e modificar assimetrias de poder. Desse modo, ao considerar que as práticas sociais orientam e são orientadas pelo discurso, os autores expõem brevemente como as novas relações afetivas mudaram as formações familiares e, em consequência, as leis e os textos que circulam no contexto familiar, jurídico, religioso e midiático. Destacam também que a crítica em ADC percorre dois caminhos: i) "valor atribuído à ética, à justiça e a decência no processo de análise”, ii) "problema social”, cujas análises se constroem sobre juízos de valores, certo e errado, por exemplo (p.13).

Ainda nesse primeiro momento, os autores abordam conceitos que serão recorrentes nos capítulos dessa coletânea, como ordens de discurso, reflexividade, agência, ideologia e hegemonia. Logo, finalizam a apresentação enumerando os passos que, conforme Chouliaraki e Fairclough (1999), são necessários para um eficiente trabalho em ADC, que, entre outras etapas, iniciam com a identificação de um problema na prática social, passam pela análise social e linguística e terminam com a reflexão acerca dos elementos da prática e sua relação com as mudanças.

Análise de discurso crítica para linguistas e não linguistas está dividido em duas partes - teoria e método -, cada uma apresentando, respectivamente, cinco e quatro capítulos, nos quais os autores explanam e exemplificam, com maestria didática, conceitos basilares que compõem a teoria social do discurso e as práticas sociais críticas. Vamos a eles!

No capítulo 1, Histórico da análise de discurso crítica, Iran Ferreira de Melo mostra ao leitor a ADC como uma forma de investigar a relação dialética entre linguagem e sociedade, bem como os efeitos que uma exerce sobre a outra nas variadas práticas discursivas. Para tanto, explica a relevância do vocábulo "crítica”, em "Análise de Discurso Crítica”, apresentado na/pela Escola de Frankfurt e que revela um posicionamento político explícito dos cientistas, cujas práticas outrora consideradas isentas de ideologia, passaram a se preocupar também com problemas sociais e buscar transformações. Tem-se, então, uma ciência denunciativa, que desvela o invisível encoberto por interesses específicos; engajada, que reflete sociolinguisticamente sobre os problemas existentes e procura solucioná-los; e pedagógica, que busca conscientizar os sujeitos acerca das coerções ocultas e orientá-los à libertação.

Melo também destaca que o termo análise de discurso crítica foi utilizado pela primeira vez por Fairclough, no artigo Critical and Descriptive Goals in Discourse Analysis, publicado em 1985 no periódico Journal of Pragmatics; todavia, somente no início da década de 1990, quando Teun van Dijk, Gunther Kress, Ruth Wodak, Theo van Leeuwen e Fairclough se reuniram em um simpósio, realizado em Amsterdã, para discutir questões linguístico-discursivas, a ADC se firmou como uma "rede internacional de estudos" (p. 29). Por fim, o autor aponta ainda seis princípios que norteiam as pesquisas em ADC: i) ímpeto crítico, ii) explicitude políticoideológica, iii) transdisciplinaridade, iv) aplicabilidade, v) acessibilidade, vi) empoderamento social, os quais contribuem para a concretização da principal preocupação faircloughiana: assuntos que dizem respeito às relações entre o discurso e a mudança social na contemporaneidade.

Solange Maria de Barros inicia o capítulo 2, Bases filosóficas da análise de discurso crítica, destacando que o marxismo ocidental, a filosofia da linguagem de Mikhail Bakhtin e o pensamento de Michel Foucault influenciaram consideravelmente os estudos críticos de Fairclough. Diretamente associados à Escola de Frankfurt, um grupo de cientistas sociais e filósofos alemães que buscava compreender, entre outras questões, como o capitalismo interfere no desenvolvimento humano, os ideais marxistas, à medida que atentavam para as condições sociais dos indivíduos, superavam "os limites do positivismo, do materialismo e do determinismo" (p.37) em prol de uma ciência emancipatória.

No que tange à filosofia bakhtiniana, Barros sublinha o aspecto social, histórico e ideológico da linguagem, o qual corrobora a máxima de que, através da palavra, os conflitos se manifestam nas estruturas sociais. Além disso, a visão polifônica da linguagem, 
com as categorias da intertextualidade e da interdiscursividade, coopera com a ADC para a compreensão das relações assimétricas de poder. Em relação a Foucault, sua principal contribuição para os estudos críticos se relaciona a temas como discurso e poder e, como consequência, a concepção de que o poder não se limita à violência/repressão, pois práticas discursivas de determinadas instituições e/ou indivíduos podem efetivá-lo.

Na sequência, Josenia Antunes Vieira e Denise Silva Macedo abrem o capítulo 3, Conceitos-chave em análise de discurso crítica, definindo a ADC como um conjunto de abordagens científicas transdisciplinares que estudam criticamente a linguagem como prática social. Ressaltam que se trata de teoria e método analítico cujo texto é a unidade mínima para a investigação da relação recíproca entre discurso e sociedade. Em seguida, as autoras discorrem sobre a origem da ADC, o que nos leva à linguística crítica (LC), abordagem desenvolvida na Inglaterra, nos anos de 1970, que une análise linguística textual à teoria social com o objetivo de explicar o funcionamento da linguagem em processos ideológicos e políticos.

Dando continuidade, Vieira e Macedo expõem conceitos basilares para a imersão em ADC: i) discurso, linguagem como uma forma de prática social, e não exclusivamente individual ou situacional; ii) poder, base da dominação que emana de um conjunto de relações sociais; iii) hegemonia, liderança dialeticamente construída por meio de alianças e consentimentos; iv) ideologia, forma como o sentido estabelece e ampara relações de subordinação.

Outro ponto de destaque discutido pelas autoras se refere ao $\mathrm{C}$ de crítica da ADC, que a diferencia da AD francesa, principalmente porque, enquanto esta concebe o sujeito como um ser assujeitado pelo próprio discurso (pelo menos, em sua primeira fase), aquela vê uma relação dialética entre ambos, o que proporciona uma prática social transformadora. Com essa perspectiva de intervenção, trabalhos em ADC examinam temas como imigração, racismo, pobreza, gênero, desigualdade social na pós-modernidade, ou modernidade tardia, e para tal nos foram apresentados três modelos de análise faircloughiana: o tridimensional, o bidimensional e o transdisciplinar, dos quais a escolha parte das demandas e especificidades do objeto e/ou do tipo de pesquisa do analista.

Por último, Vieira e Macedo mencionam o impacto das novas tecnologias da informação e do conhecimento (TICs) nos textos, o que ocasionou uma ampliação conceitual destes, para além do escrito e falado, e instaurou uma recente linha de pesquisa: a teoria da semiótica social da multimodalidade (TSSM), da qual os principais colaboradores são Kress e van Leeuwen com a obra Reading Images: the Grammar of Visual Design (2006).

No capítulo 4, Discurso e prática social, Paulo Roberto Gonçalves-Segundo inicia o debate ao eleger o caráter reflexivo que leva à transformação social como o aspecto central de uma ciência crítica. Para isso, nos apresenta o modelo tridimensional de Fairclough a fim de que compreendamos as relações existentes entre agentes, estruturas, práticas, textos e eventos na ADC. Gonçalves-Segundo destaca de Chouliaraki e Fairclough (1999) a definição de que as práticas sociais são modos rotineiros, interligados a espaços e tempos particulares, através dos quais os indivíduos agem coletivamente no mundo; por conseguinte, “[...] elas consistem em pontos de articulação entre a estruturação e a construção, entre a coerção e a agência” (p. 84).

O autor cita também a visão de Giddens (2009) sobre ideologia, forma de representação simbólica capaz de legitimar assimetrias de dominação, a qual remete, em maior ou menor grau, ao conceito de habitus de Bourdieu, ou seja, à formação sociolinguística dos falantes. Desse modo, as ideologias colaboram para a naturalização, baseadas no consenso, de determinadas práticas desiguais de poder. Temos assim práticas sociais ideologicamente hegemônicas: alvo das pesquisas em ADC. Sendo a língua um sistema dinâmico e aberto, que se adapta a uma gama de possibilidades, Gonçalves-Segundo salienta a capacidade das ordens do discurso, que são responsáveis pelo controle linguístico, pela organização social e, consequentemente, pela construção de significados dos sujeitos que (inter)agem em sociedade. Para finalizar, o autor aborda questões relativas ao enfraquecimento das tradições, ao desenvolvimento tecnocientífico e à conversacionalização do discurso, processos vigentes na contemporaneidade, na geração dos shoppings-centers e do WhatsApp.

No capítulo 5, Teoria social do discurso e evolução da análise de discurso crítica, Luciane Cristina Eneas Lira e Regysane Botelho Cutrim Alves justificam que o recente interesse das ciências sociais pelos estudos linguísticos resulta da compreensão da linguagem como um fator constituinte e constitutivo da vida em sociedade, quer seja como reflexão das escolhas feitas por homens e mulheres, 
quer seja como promoção das ações sociais. Sendo assim, diante de inúmeras assimetrias referentes a gênero, identidade, ideologia e poder, fazem-se necessários distintos olhares investigativos e transdisciplinares para o descortinamento dessas questões.

Semelhante a capítulos anteriores, Lira e Alves trazem a didática concepção tridimensional de Fairclough - prática social, prática discursiva e texto -, e a associam a momentos de explicação, interpretação e descrição, respectivamente. Aspectos pertinentes à produção, à distribuição e ao consumo textual são apontados pelas autoras tanto como reprodutores de ideologias dominantes quanto transformadores da realidade, nem sempre justa e ética. Em ADC, a mudança discursiva que pode gerar mudança social, e vice-versa, ocorre em duas perspectivas: reestruturação entre os campos e domínios discursivos e reescala entre o local versus o global

De maneira precisa, assim como em outros capítulos, Lira e Alves também frisam as contribuições do realismo crítico e da linguística sistêmico-funcional para a pesquisa comprometida e emancipatória da ADC; e acrescentam a etnografia como uma estratégia eficiente para ampliação do corpus com dados complementares. Finalizam o último capítulo teórico discutindo as críticas associadas à ADC e a seu desenvolvimento: a principal delas se refere ao conceito de ideologia, cujas bases perpassam a concepção da luta de classes de Marx e chegam ao caráter eminentemente negativo de Thompson (1990).

Ao iniciar a parte da obra que se dedica a discutir aspectos metodológicos da ADC, Décio Bessa e Denise Tamaê Borges Sato trazem Categorias de análise, no capítulo 6, e mostram os "[...] aspectos semióticos e dialéticos nas diferentes formas de existir da ideologia, situando-as em uma estrutura de poder" (p. 126). A seguir, apontam os caminhos pelos quais os analistas da ADC dialéticorelacional perpassam em seus trabalhos: começam com a identificação de um problema social que interfere nas ordens do discurso; em seguida, passam à busca por elementos semióticos; para, finalmente, realizarem a reflexão/compreensão da prática social.

Os autores utilizam a pesquisa realizada por Bessa em 2007, Charges eletrônicas das eleições 2006: uma análise de discurso crítica, para explicar e exemplificar sucintamente as seguintes categorias analíticas: gênero discursivo, intertextualidade, significado de palavras, representação de atores sociais e interdiscursividade. Esse momento é de grande importância para pesquisadores e/ou futuros pesquisadores, em particular, os mais inexperientes, que podem ficar inseguros quanto à definição das categorias a serem analisadas, pois ainda não compreendem que elas dependem das exigências do corpus de suas investigações.

Por sua vez, em Análise de discurso da mídia, capítulo 7, André Ricardo Nunes Martins declara que a mídia tem papel preponderante na vida social das pessoas na maioria dos países capitalistas e, por tal razão, há uma gama de pesquisas em ADC que utilizam textos oriundos dos variados meios de comunicação de massa. Inicialmente, Nunes discute a popularização da imprensa escrita e falada, a partir da segunda metade do século XX, a qual constrói imagens representativas dos grupos e atores sociais em disputa no domínio público. Atrelada a mudanças econômicas, sociais e culturais e ao avanço das TICs (a internet, em especial), as redes sociais contribuem para a naturalização de consensos, nos quais o uso da linguagem favorece um determinado segmento social ou alguma perspectiva particular.

Em seguida, o autor cita trabalhos de pesquisadores que investigam problemas sociais e políticos através do discurso midiático, por exemplo: o discurso da mídia sobre as populações em situação de rua, de Bessa (2009, 2013, 2014); o discurso da violência na imprensa, de Ottoni (2013); as representações de negros na mídia impressa do século XX, de Lima (2013); o ativismo LGBT, de Melo (2013). Diante desse leque de possibilidades temáticas que a ADC nos permite investigar e com o intuito de auxiliar o leitor, atual/futuro pesquisador, Nunes elabora questionamentos imprescindíveis sobre o fazer teórico-metodológico: i) que material será trabalhado?; ii) qual abordagem será utilizada?; iii) quais marcas linguísticas e discursivas comporão a materialidade da pesquisa?; iv) quanto tempo será necessário para a execução do trabalho e qual será o recorte temporal para a coleta do corpus?; v) de que modo será feita a interpretação e a análise dos dados? Por fim, o autor ilustra esses tópicos com uma relevante pesquisa em ADC, com o gênero jornalístico cartas do leitor, a qual investiga como os leitores compreendem a impunidade, identificam-na no país e se posicionam em relação a ela.

Denise Tamaê Borges Sato e José Ribamar Lopes Batista Jr., no capítulo 8, Análise de discurso das práticas: etnografia, tratam dos laços teórico-metodológicos entre a ADC e a etnografia com vistas à reflexão acerca das contribuições das atividades de campo para 
a concretude de uma análise mais consistente e transformadora. Os autores começam a discussão retomando, de maneira bastante clara, os conceitos de práticas sociais, "[...] formas relativamente estáveis de se fazer algo", de texto, "ferramenta para a produção de ações" que carrega consigo pressupostos, valores e crenças, e de discurso "um dos elementos da prática social” (p. 185- 186). Percebese, assim, que a ADC se preocupa com os efeitos do discurso: instalar, manter e perpetuar o poder na sociedade. Posteriormente, diferem a etnografia crítica da etnografia tradicional, pois, enquanto esta tenta compreender a sociedade como um todo ou parte dela, aquela defende as camadas oprimidas e investiga os modos de funcionamento do poder em prol da reflexividade e da transformação.

Para concluir o capítulo, Sato e Batista Jr. descrevem o trabalho etnográfico realizado por Heath, em 1969, que analisou a aprendizagem de meninos e meninas em duas comunidades do interior dos Estados Unidos. Com essa empreitada, foi possível verificar que todas as crianças, independentemente de serem brancas ou negras, não aprendiam o inglês padrão devido à falta de compreensão da dinâmica escolar. A partir dessa pesquisa, Heath desenvolveu o conceito de evento de letramento, auxiliou significativamente as pesquisas em educação e desenhou um quadro de planejamento investigativo bastante útil à ADC.

No capítulo 9, Por uma análise de discurso crítica consistente, Solange de Carvalho Lustosa mostra os sete erros mais comuns que devem ser evitados ao fazer ADC. São eles: i) desconsiderar uma fundamentação teórico-metodológica que permita a interface entre várias ciências, invalidando seu caráter transdisciplinar; ii) analisar apenas os elementos linguísticos em textos multimodais, ignorando as potencialidades das demais semioses; iii) considerar que faz etnografia simplesmente porque estar junto a um grupo e, com isso, deixar-se contaminar por relações de poder, impondo as próprias verdades, consideradas absolutas, ao pesquisado/entrevistado; iv) generalizar conceitos e categorias analíticas relacionados ao objeto de pesquisa; v) privilegiar a análise linguística em detrimento da social ou vice-versa, ocultando a simbiose entre linguagem e sociedade; vi) esquecer o caráter ético e colaborativo dos trabalhos, favorecendo a coação dos sujeitos envolvidos; vii) elaborar dados falhos prejudicando a consistência dos resultados. Lustosa ressalta que tais equívocos podem fortalecer estereótipos, silenciar ou descrever equivocadamente grupos sociais. Portanto, seria importante evitá-los.

Em síntese, a obra resenhada constitui um exemplo do grande interesse entre linguistas e não linguistas pelo desenvolvimento de pesquisas discursivas de natureza crítico-transdisciplinar, as quais, de modo teórico e prático, discutem os efeitos constitutivos da relação entre linguagem, sociedade e poder. Arriscamo-nos dizer que, para os iniciantes em ADC, o livro serve de verdadeira bússola para a compreensão dessa complexa e instigante abordagem de análise do discurso, tanto pela linguagem clara e didática dos autores, quanto pela recorrência de conceitos imprescindíveis que atravessam brilhantemente os seus nove capítulos. Portanto, recomendamos a leitura de Análise de discurso crítica para linguistas e não linguistas, bem como defendemos o seu mérito perante os muitos desafios que estudantes, professores e pesquisadores enfrentam na atualidade para uma construção ética e justa do conhecimento.

\section{() (1) $\circledast \Theta$}

Recebida em 06/05/2020. Aceita em 16/03/2021. 